\title{
Endemic and Rare Taxa of Ulubaba Mountain (Adiyaman) Vegetation Structure and Their Evaluation According to IUCN Categories
}

\author{
Ahmet Zafer TEL ${ }^{1}$, Ahmet ŞIMSSEK² \\ ${ }^{1}$ Adryaman University, Faculty of Science and Art, Department of Biology, Adiyaman, Turkey \\ ${ }^{2}$ Adryaman University, Institute of Science, Section of Biology, Adryaman, Turkey
}

\begin{abstract}
Received: 29.11 .2017
Accepted: 28.12 .2017

Available online: 29.12 .2017

Published: 29.12 .2017

Abstract: This study was carried out between 2013-2015. Ulubaba Mountain is within the borders of Adiyaman province. During syntaxonomic studies, 48 families, 141 genera and 228 taxa were detected. 48 of the detected taxa are endemic. According to the data, endemism rate of the research area is $21,05 \%$. In addition, two rare non-endemic taxa in the threatened categories have been identified. A total of 50 endemic and rare taxa categories are as follows: 4 taxa critically endangered (CR), 7 taxa endangered (EN), 4 taxa vulnerable (VU), 6 taxa near threatened (NT), 27 taxa least concern (LC) and 2 taxa data deficient (DD).
\end{abstract}

Keywords: Ecology, Flora, Syntaxonomy, Red List

\section{Ulubaba Dağı'nın (Adıyaman) Vejetasyon Yapısının Endemik ve Nadir Taksonları ve Bunların IUCN Kategorilerine Göre Değerlendirilmesi}

Özet: Bu çalışma 2013-2015 yılları arasında yapılmıştır. Ulubaba Dağı, Adıyaman il sınırları içindedir. Sintaksonomik çalışmalar esnasında 48 familya, 141 cins ve 228 takson tespit edilmiştir. Tespit edilen taksonların 48 tanesi endemiktir. Bu verilere göre araştırma alanının endemizm oranı \% 21,05' tir. Ayrıca tehlike kategorilerinde yer alan ve endemik olmayan 2 nadir takson tespit edilmiştir. Endemik ve nadir toplam 50 taksonun tehlike kategorileri şöyledir: 4 takson kritik (CR), 7 takson tehlikede (EN), 4 takson duyarlı (VU), 6 takson tehdide açık (NT), 27 takson düşük riskli (LC) ve 2 takson yetersiz verili (DD).

Anahtar kelimeler: Ekoloji, Flora, Sintaksonomi, Kırmızı Liste

\section{Giriş}

Ilıman iklim kuşağında yer alan Türkiye Florasının takson sayısı Sinan (2014) verilerine göre 11707'dir. Bu taksonlardan 3649 tanesi endemiktir. Bu rakamlara göre Türkiye florasının endemizm oranı \% 31,17' dir.

Eğreltiler dâhil 11707 bitki taksonuna sahip olan ülkemiz diğer yakın ülkeler ile karşılaştırıldığında floristik kompozisyonunun oldukça yüksek olduğu görülmektedir. Bazı komşu ülkelerin sahip oldukları tohumlu bitki sayıları İran 8000, Yunanistan 5000, Irak 4000, Bulgaristan 3650, Suriye-Lübnan 3000, Kıbris 2000 ve bütün Avrupa kıtasında 12000 olduğu göz önüne alınırsa Türkiye florasının zenginliği daha iyi anlaşılır. Ayrıca Türkiye'nin 10 mislinden fazla yüzölçümüne sahip bütün Avrupa kıtasında 2500 kadar endemik bitkinin bulunduğu göz önüne alınırsa; Türkiye'nin endemizm oranının yüksekliği daha çok dikkati çeker (Tel 2001).

Araştırma alanımıza yakın çevrede yapılan çalışmalarda; Tel (2009) Nemrut Dağı Florası üzerine yaptığı araştırmada 43 endemik takson tespit etmiş olup endemizm oranı \% 17,2' dir. Tel ve ark. (2010) tarafından Nemrut Dağı Vejetasyonu üzerine yapılan çalışmada 46 endemik takson tespit edilmiş olup endemizm oranı \% 18,6'dır. Tel ve Tak (2015) Çat Barajı Havzasında yaptıkları sintaksonomik çalışmada 167 tür ve tür altı takson tespit etmiş olup endemizm oranını \% 12 olarak belirlenmiştir. Eğilmez ve Tel (2016) Gölbaşı Gölleri Havzası vejetasyonu üzerine yaptıkları çalışmada 136 takson tespit etmiş, endemizm oranını ise \% 5 olarak belirlemişlerdir.

Bu çalışmanın amacı Ulubaba Dağı'nı (Adıyaman) endemik ve nadir taksonlar bakımından analiz edip değerlendirmektir. Bu bağlamda araştırma alanındaki endemik ve nadir taksonlar tespit edilip bunların IUCN tehlike kategorileri belirlenmiştir. Böylece bölgede yapılabilecek tür eylem planlarına ve alınabilecek koruma tedbirlerine yön verilmesine yardımcı olmak amaçlanmıştır.

\section{Materyal ve Metod}

Bu çalışma 2013 - 2015 yıllarında çalışma alanının vejetasyonunun optimum gelişme gösterdiği dönem olan Haziran - Temmuz aylarında yapılmıştır.

Araştırma alanı olarak belirlenen Ulubaba Dağı (Adiyaman), Güneydoğu Toroslar üzerinde ve $2533 \mathrm{~m}$ yüksekliğe sahiptir. Koordinatları $37^{\circ} 56^{\prime} 54^{\prime \prime}$ Kuzey enlemi ile $38^{\circ} 09^{\prime} 01^{\prime \prime}$ Doğu boylamıdır. Ulubaba Dağ1 (Adıyaman)' nın güneyinde Adıyaman İ Merkezi, Güneybatısında Adıyaman'ın Tut İlçesi, Kuzeydoğusunda Adıyaman'ın Çelikhan İlçesi, Kuzeybatısında ise Malatya'nın Doğanşehir İlçesi yer almaktadır. Çelikhan İlçesi'ne $20 \mathrm{~km}$, Adıyaman il merkezine yaklaşık $65 \mathrm{~km}$, Tut İlçesi'ne $105 \mathrm{~km}$ ve Malatya'nın Doğanşehir İlçesine $42 \mathrm{~km}$ mesafededir. Ulubaba Dağı, zirvesindeki Seyyid Battal Gazi'nin babası Hüseyin Gazi'ye ait olduğu söylenen Ulubaba Türbesi nedeniyle bu ismi almıştır (Şekil 1). 


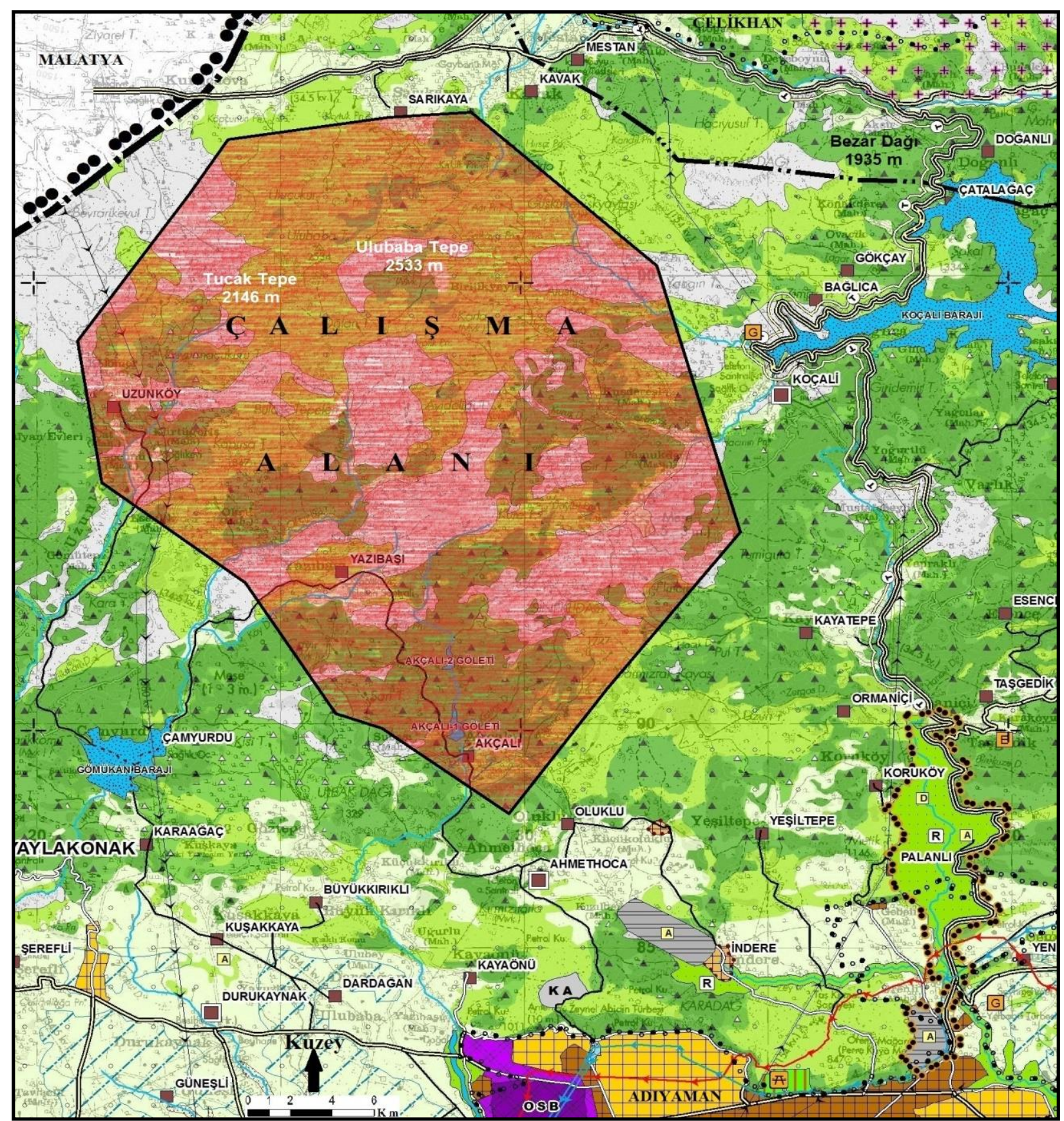

Şekil 1: Çalışma alanını gösteren harita

Ulubaba Dağı'nın kuzey yamacında Sarıkaya (Çig) Köyü, güneybatısında Yazıbaşı (Azikan) Köyü, Uzunköy (Dilikan), Çamyurdu (Gömükan) ve güneyinde Akçalı Köyleri olmak üzere birçok yerleşim merkezi yer almaktadir.

Araştırma Alanı, Türkiye Grid Sistemi Haritasının C7 karesinde yer almaktadır. Ayrıca İran-Turan ve Akdeniz fitocoğrafik bölgelerinin kesiştiği bir alanda yer almaktadır. $\mathrm{Bu}$ nedenle farklı fitocoğrafik bölge elementlerine de ev sahipliği yapmaktadır.

$\mathrm{Bu}$ çalışmada araştırma alanında homojen dağılım gösteren orman ve step vejetasyonlarına ait tespit edilen her bitki birliği için 10 örnek parselden bitki örnekleri alınmıştır. Örneklerin çiçek, meyve, kök ve yapraklarıyla birlikte toplanmasına özen gösterilmiştir. Her örnek kurutma tekniklerine uygun bir şekilde kurutulmuştur. Kurutma işleminden sonra örnekler incelenerek teşhis edilmiştir.

Bitki teşhisleri P. H. Davis'in (1965-1988; Davis ve ark 1988) 'Flora of Turkey and the East Aegean Island' adlı eserinden ve Güner ve ark. (2000)'nın bu esere suplementer olarak yayınlanan eserinden yararlanılarak yapılmıştır. Ayrıca bitkilerin karakterlerinin belirlenmesinde 'Bitki bilimi Terimleri Sözlüğü' adlı eserden yararlanılmıştır (Altınayar 1987). Tanımlanan endemik türlerin tehlike kategorileri, Ekim ve ark. (2000) tarafından hazırlanan "Türkiye Bitkileri Kırmızı Kitabı" ve "IUCN Red List Categories" adlı eserlerden yararlanılarak belirlenmiştir (IUCN 2011). 
Tablo 1: Çalışma alanından toplanan endemik ve nadir taksonların familyaları, fitocoğrafik bölgeleri, hayat formları ve IUCN tehlike kategorileri

\begin{tabular}{|c|c|c|c|c|}
\hline Sira No & Takson Adı & $\begin{array}{c}\text { IUCN Tehlike } \\
\text { Kategorisi }\end{array}$ & Fitocoğrafik Bölge & Hayat \\
\hline \multicolumn{5}{|c|}{ APIACEAE } \\
\hline 1. & Pimpinella paucidentata Matthews & $-/ \mathrm{VU}$ & İran - Turan & $\mathrm{H}$ \\
\hline 2. & Tordylium cappadocicum Boiss. & End. / DD & İran - Turan & \\
\hline \multicolumn{5}{|c|}{ ASTERACEAE } \\
\hline 3. & Cousinia foliosa Boiss. \& Ball. & End. / LC & İran - Turan & H \\
\hline 4 . & Centaurea urvillei DC. subsp. nimrodis (Boiss. \& Hausskn.) Wagenitz & End. / LC & İran - Turan & $\mathrm{F}$ \\
\hline 5. & Helichrysum arenarium (L.) Moench subsp. aucheri(Boiss.) Davis \& Kupica & End. / LC & İran - Turan & $\mathrm{r}$ \\
\hline 6. & Ifloga spicata (Forssk.) Schultz Bip. & $-/ \mathrm{EN}$ & - & $\mathrm{H}$ \\
\hline 7. & Serratula oligocephala DC. & End. / LC & İran - Turan & $\mathrm{H}$ \\
\hline 8. & Tanacetum cadmeum (Boiss.) Heywood subsp. orientale Grierson & End. / LC & İran - Turan & 1 \\
\hline 9. & Tanacetum densum (Lab.) Schultz Bip. subsp. amani Heywood & End. / LC & İran - Turan & 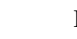 \\
\hline 10. & Tragopogon fibrosus Freyn \& Sint. Ex Freyn & End. / EN & - & I \\
\hline
\end{tabular}

\section{BORAGINACEAE}

$\begin{array}{lllr}\text { 11. } & \text { Onosma isauricum Boiss. \& Heldr. } & \text { End. / LC } & \text { İran - Turan } \\ \text { 12. } & \text { Paracaryum cappadocicum Boiss. \& Bal. } & \text { End. / LC } & \text { İran - Turan } \\ \text { 13. } & \text { Paracaryum polycarpum (Rech. fil.) R.Mill } & \text { End. / CR } & \text { Doğu Akdeniz }\end{array}$

\section{BRASSICACEAE}
14. Aethionema lepidioides Huber-Morath
15. Alyssum harputicum Dudley
16. Alyssum pateri Nyar. subsp. pateri
17. Alyssum stylare (Boiss. \& Balansa) Boiss.
18. Erysimum sintenisianum Bornm.
19. Isatis aucheri Boiss.

\section{CARYOPHYLLACEAE}

$\begin{array}{llc}\text { End. / EN } & \text { İran - Turan } & \mathrm{T} \\ \text { End. / CR } & \text { İran - Turan } & \mathrm{H} \\ \text { End. / LC } & \text { İran - Turan } & \mathrm{H} \\ \text { End. / LC } & \text { İran - Turan } & \mathrm{T} \\ \text { End. / DD } & \text { İran - Turan } & \mathrm{H} \\ \text { End. / LC } & \text { İran - Turan } & \mathrm{H}\end{array}$

End. / LC

\section{FABACEAE}
24. Astragalus kurdicus Boiss. var. muschianus (Kotschy \& Boiss.)
24. Chamberlain.
25. Hedysarum pogonocarpumBoiss.
26. Lotus gebelia Vent. var. anthylloides Boiss.

End. / NT

İran - Turan

K

End. / LC

$\mathrm{H}$

End. / NT

İran - Turan

$\mathrm{H}$

\section{LAMIACEAE}
27. Cyclotrichium niveum (Boiss.) Manden. \& Scheng.
28. Marrubium globosum Montbret \& Aucher ex Bentham subsp. globosum
29. Phlomis armeniaca Willd.
30. Phlomis capitata Boiss.
31. Scutellaria orientalis L. subsp. alpina (Boiss.) O. Schwarz var. alpina
32. Scutellaria orientalis L. subsp. haussknechtii(Boiss.) Edmonson

End. / VU

İran - Turan

H

End. / LC

End. / EN

İran - Turan

K

End. / LC

İran - Turan

K

End. / NT

İran - Turan

K

End. / LC

İran - Turan

K 
Tablo 1 (devam)

\begin{tabular}{|c|c|c|c|c|}
\hline Sira No & Takson Adı & $\begin{array}{c}\text { IUCN Tehlike } \\
\text { Kategorisi }\end{array}$ & Fitocoğrafik Bölge & Hayat Formu \\
\hline 33. & Scutellaria salviifolia Bentham & End. / LC & - & K \\
\hline 34. & Stachys ramosissima Montbret \& Aucher ex Bentham var. ramosissima & End. / CR & İran - Turan & $\mathrm{H}$ \\
\hline 35. & Thymus brachychilus Jalas & End. / LC & İran - Turan & K \\
\hline \multicolumn{5}{|c|}{ LILIACEAE } \\
\hline 36. & Allium scabriflorum Boiss. & End. / LC & İran - Turan & G \\
\hline \multicolumn{5}{|c|}{ MALVACEAE } \\
\hline 37. & Alcea apterocarpa (Fenzl) Boiss. & End. / LC & İran - Turan & $\mathrm{H}$ \\
\hline \multicolumn{5}{|c|}{ PAPAVERACEAE } \\
\hline 38. & Papaver fugax Poiret var. platydiscus Cullen & End. / LC & İran - Turan & $\mathrm{H}$ \\
\hline 39. & Papaver persicum Lindl. subsp. fulvum Kit Tan \& Sorger & End. / LC & İran - Turan & $\mathrm{T}$ \\
\hline \multicolumn{5}{|c|}{ PLUMBAGINACEAE } \\
\hline 40. & Acantholimon acerosum (Willd.) Boiss. var. parvifolium Bokhari & End. / VU & İran - Turan & K \\
\hline 41. & Acantholimon spirizianum Mobayen var. multiflorum Bokhari & End. / CR & İran - Turan & K \\
\hline \multicolumn{5}{|c|}{ POACEAE } \\
\hline 42. & Poa pseudobulbosa Bor & End. / EN & Doğu Akdeniz & $\mathrm{H}$ \\
\hline \multicolumn{5}{|c|}{ ROSACEAE } \\
\hline 43. & Prunus kurdica Fenzl. Ex Fritzch & End. / EN & İran - Turan & Mi.F \\
\hline \multicolumn{5}{|c|}{ RUBIACEAE } \\
\hline 44. & Asperula serotina (Boiss. \& Heldr.) Ehrend. & End. / NT & Doğu Akdeniz & $\mathrm{H}$ \\
\hline \multicolumn{5}{|c|}{ SANTALACEAE } \\
\hline 45. & Thesium tauricolum Boiss. \& Hausskn. & End. / NT & İran - Turan & $\mathrm{H}$ \\
\hline \multicolumn{5}{|c|}{ SCROPHULARIACEAE } \\
\hline 46. & Scrophullaria cryptophila Boiss. \& Heldr. & End. / LC & Doğu Akdeniz & $\mathrm{H}$ \\
\hline 47. & Scrophullaria libanotica Boiss. var. urartuensis R. Mill & End. / LC & İran - Turan & $\mathrm{H}$ \\
\hline 48. & Scrophullaria libanotica Boiss. subsp. armena R. Mill & End. / NT & İran - Turan & $\mathrm{H}$ \\
\hline 49. & Verbascum ballisianum Murb., Nachtr., Monogr. & End. / EN & İran - Turan & $\mathrm{H}$ \\
\hline 50. & Veronica orientalis Miller subsp. nimrodi (Richter ex Stapf) M.A. Fischer & End. / LC & - & $\mathrm{K}$ \\
\hline
\end{tabular}

Tablo 2: Araştırma alanı ve yakın çevrede yapılmış bazı çalışmaların endemizm oranları

\begin{tabular}{lc}
\hline Çalışmanın Adı & $\begin{array}{c}\text { Endemizm } \\
\text { oranı (\%) }\end{array}$ \\
\hline Çalı̧̧ma alanı & 21,05 \\
Ali Dağı ve Ziyaret Tepesi (Adıyaman) Vejetasyonu (Tel ve Şahin 2016) & 7,3 \\
Çelikhan Çat barajı (Adıyaman)'ın Fitoekolojik ve Fitososyolojik özellikleri (Tel ve Tak 2015) & 12 \\
Gölbaşı Gölleri (Adıyaman) Havzası́nın Vejetasyonu (Eğilmez ve Tel 2016) & 5 \\
Perre (Pirin) Antik Şehri (Adıyaman) Vejetasyonu (Tel ve Tak 2012) & 11 \\
Nemrut Dağı vejetasyonu (Tel ve ark 2010) & 18,6 \\
Karacadağ Vejetasyonu (Kaya 2006) & 6,34 \\
\hline
\end{tabular}




\section{Sonuçlar ve Tartışma}

Araştırma alanında 8'i step ve alpin step, 4'ü orman ve çalı vejetasyonlarına ait 12 bitki birliği tespit edilmiştir. Bunların tamamı bilim dünyası için yeni olan bitki birlikleridir. Her bir birlik için belirlenen 10 ayrı kuadrattan toplanan bitkiler incelendiğinde 48 farklı familyanin 141 cins ile ve bu cinslerin de toplam 228 farklı tür ve tür altı taksonla temsil edildiği görülmüştür. $\mathrm{Bu}$ taksonlardan 48 tanesi endemiktir. Endemizm oranı \%21,05'tir. Araştırma alanındaki endemik olmayan 2 nadir taksonun da IUCN tehlike kategorilerinde yer aldığ1 tespit edilmiştir (Tablo 1).

Araştırma alanımıza yakın çevrede yapılan çalışmalardan Tel ve ark. (2010), 4 vejetasyon tipine ait 7 birlik, 3 alt birlik ve 1 kominite tespit etmişlerdir. Bu araştırmada, 46 endemik tür tespit edilmiş olup endemizm oranı \% 18,6' dir. Tel (2009), 43 endemik takson tespit araştırma alanında endemizm oranı \% 17,2' dir. Egilmez ve Tel (2016), çalışma alanında 39 familya, 109 cins ve 136 taksa tespit etmiştir. Bu taksonlardan 21 tanesinin C6 karesi için yeni olduğu sonucuna ulaşmıştır. Araştırma alanının endemizm oranını ise \% 5 olarak hesaplamıştır.

Tel ve Tak (2015), çalışmasında 34 familya, 115 cins ile 167 tür ve tür altı takson tespit etmiştir. Araştırma alanının endemizm oranını ise \% 12 olarak hesaplamıştır.

Çalışma alanından toplanıp tanımlanan 228 taksonun 48 tanesi endemiktir. Buna göre çalışma alanının endemizm oranı \% 21,05'dir. Çalışma alanına yakın çevrede yapılan bazı çalışmalarda elde edilen endemizm oranlarıyla karşılaştırıldığında, çalışma alanının endemizm oranının daha yüksek olduğu görülmüştür (Tablo 2).

Endemik ve nadir toplam 50 taksonun tehlike kategorileri şöyledir: 4 takson kritik (CR), 7 takson tehlikede (EN), 4 takson duyarlı (VU), 6 takson tehdide açık (NT), 27 takson düşük riskli (LC) ve 2 takson yetersiz verili (DD) (Tablo 3).

Tablo 3: Çalışma alanındaki endemik ve nadir taksonlara ait IUCN Tehlike kategorilerine dağılımı

\begin{tabular}{lll}
\hline $\begin{array}{l}\text { IUCN Tehlike } \\
\text { Kategorisi }\end{array}$ & $\begin{array}{l}\text { Tür } \\
\text { Sayıs }\end{array}$ & $\begin{array}{l}\text { Yüzdelik } \\
\text { Oranı }\end{array}$ \\
\hline CR & 4 & $\% 8,51$ \\
EN & 7 & $\% 12,77$ \\
VU & 4 & $\% 6,38$ \\
NT & 6 & $\% 12,77$ \\
LC & 27 & $\% 55,32$ \\
DD & 2 & $\% 4,25$ \\
\hline
\end{tabular}

Çalışma alanındaki endemik ve nadir taksonların 39 tanesi İran - Turan, 4 tanesi Doğu Akdeniz elementidir. Avrupa - Sibirya fitocoğrafik bölgesinden herhangi bir takson bulunmamaktayken herhangi bir fitocoğrafik bölge elementi olmayan 7 takson bulunmaktadır (Tablo $4)$.

Çalışma alanındaki 50 endemik ve nadir taksonun 30 tanesi hemikriptofit, 14 tanesi kamefit, 4 tanesi terofit, 1 tanesi geofit ve kalan 1 tanesi de mikro fanerofit formundadir (Tablo 5).

Tablo 4: Çalışma alanındaki endemik ve nadir taksonların fitocoğrafik bölgelere dağılımları

\begin{tabular}{lll}
\hline Fitocoğrafik Bölgenin Adı & Tür Sayısı & Yüzdelik oranı \\
\hline İran - Turan & 39 & $\% 78$ \\
Doğu Akdeniz & 4 & $\% 8$ \\
Avrupa - Sibirya & - & $\%-$ \\
Bilinmeyen & 7 & $\% 14$ \\
\hline
\end{tabular}

Tablo 5: Çalışma alanındaki endemik ve nadir taksonların hayat formu dağılımları

\begin{tabular}{lcc}
\hline Hayat Formu & Tür Sayısı & Yüzdelik Oranı \\
\hline Terofit & 4 & $\% 8$ \\
Geofit (Kriptofit) & 1 & $\% 2$ \\
Hemikriptofit & 30 & $\% 60$ \\
Kamefit & 14 & $\% 28$ \\
Mikro Fanerofit & 1 & $\% 2$ \\
\hline
\end{tabular}

Yapılan çalışma neticesinde, bölgede yapılabilecek tür eylem planları ve alınabilecek koruma tedbirlerine yön verebilmek amacıyla şu öneriler sunulmaktadır:

CR tehlike kategorisinde yer alan 4 takson (Paracaryum polycarpum (Rech. fil.) R. Mill, Alyssum harputicum Dudley, Stachys ramosissima Montbret \& Aucher ex Bentham var. ramosissima ve Acantholimon spirizianum Mobayen var. multiflorum Bokhari) için "tür eylem planı" çalışması yapılması gerekmektedir.

VU, EN ve CR kategorisinde 15 takson bulunmaktadir. Bu kategorilerde yer alan taksonlar için koruma tedbirlerinin alınması yerinde olacaktır.

Yapılan arazi çalışmaları sırasında görülen hayvan otlatma faaliyetlerinin buradaki nesli tehlike altında olan türlerin devamlılığı konusunda ne denli büyük bir tehdit oluşturduğu aşikârdır. Bölge halkının konu hakkında bilinçlendirilmesi amaciyla ilgili kurum ve kuruluşların çalışmalar yapması gerekmektedir.

Arazi çalışmaları sırasında anız yakma amacıyla yakılmış ve kontrolden çıkmış bir yangına rastlanmıştır. $\mathrm{Bu}$ ve benzeri yangınlar bölgedeki floranın ve hatta faunanın devamlılı̆̆1 konusunda önemli bir tehdit oluşturmaktadır. Bu konuda da yerel halkın bilinçlendirilmesi için ilgili kurum ve kuruluşların çalışmalar yapması gerekmektedir.

\section{Kaynaklar}

Altınayar, G. 1987: Bitki Bilimleri Terimleri Sözlüğü. DSİ. Basım foto-film İşt. Müd. matbaası, Ankara.

Davis, P. H. 1965-1985: Flora of Turkey and the East Aegean Islands. Vol.; 1-9. Edinburgh University Press, Edinburgh.

Davis, P. H. Mill., R. R. Tan, K. (eds.) 1988: Flora of Turkey and the East Aegean Islands (supplement), Edinburgh, Edinburgh Univ. Press, Vol. 10 . 
Egilmez, Ç., Tel, A. Z. 2016: Gölbaşı Gölleri Havzası'nın (Adıyaman) Vejetasyonu. Biyoloji Bilimleri Araştırma Dergisi (BİBAD), Nobel Bilimsel Dergileri, 9 (2): 33-50.

Ekim, T., Koyuncu, M., Vural, M., Duman, H., Aytaç, Z. ve Adıgüzel, N. 2000: "Türkiye Bitkileri Kırmızı Kitabı", Ankara, Türkiye Tabiatını Koruma Derneği ve Van 100.Yıl Üniversitesi. Çevre Düzeni Planı

Güner, A., Özhatay, N., Ekim, T. Baser, K. H. C. (eds.) 2000: Flora of Turkey and the East Aegean Islands (supplement), Edinburgh, Edinburgh Univ. Press, Vol. 11.

IUCN 2011: Red List Categories: Version 3.1. Prepared by the IUCN Species Survial Commission. IUCN, Gland Switzerland and Cambridge, UK.

Kaya, Ö. F. 2006: Karacadağ (Şanlıurfa/Diyarbakır)'ın Bitki Ekolojisi ve Bitki Sosyolojisi Yönünden Araştırılması, Doktora Tezi, Ankara.

Sinan, A. 2014: Altıkardeş Dağı ve Çevresinin (Genç-Bingöl) Florası, Yüksek Lisans Tezi, Bingöl Üniversitesi, Bingöl.

Tel, A. Z., Şahin, M. S. 2016: Ali Dağı ve Ziyaret Tepesi (Adıyaman/Türkiye) Vejetasyon Tiplerinin Kompozisyonu üzerine Bir Araştırma, Adyutayam, Cilt 4, Sayı 1: 1-19.

Tel, A. Z., Tak, M. 2015: Some endemic plants of Çelikhan Çat Dam Basin (Adıyaman). Adyutayam, Cilt 3, Sayı 2: 1-6.

Tel, A. Z. 2001: Nemrut dağı (Adıyaman) vejetasyonu. Doktora tezi, Yüzüncü Yıl Üniversitesi, Van.

Tel, A. Z. 2009: Contributions to the flora of Nemrut Mountain (Adiyaman/Turkey). BioDiCon, 2/1 (2009) 36-60.

Tel, A. Z., Tatlı, A., Varol, Ö. 2010: Phytosociological structure of Nemrut Mountain (Adıyaman/Turkey). Türk Jornal of Botany, 34: 417-434.

Tel, A. Z. ve Tak, M. 2012: Perre (Pirin) Antik Şehri (Adıyaman) Vejetasyonu. Biyoloji Bilimleri Araştırma Dergisi, 5 (2): 45-62. 